\title{
An Approach to Design and Development of a Wideband Direction Finder Simulator
}

\author{
Ivan Pokrajac ${ }^{1)}$ \\ Predrag Okiljević ${ }^{1)}$ \\ Nadica Kozić ${ }^{1)}$
}

\begin{abstract}
In order to provide a tool for design and development of wideband direction finders (WDFs), a simulator of WDF has been proposed in this paper. The aim of this work is to give a hands-on-experience to researchers, students (in laboratory sessions), and to train users of WDF. The simulator consists of two main parts: the first part for generating a superposed signal on the direction finder's antenna array output, and the second part for simulation of signal acquisition and signal processing (implementation of methods for direction of arrival - DOA estimation). Using the proposed simulator, researchers have the possibility to generate various scenarios in radio frequency (RF) spectrum with different kinds of emissions. The simulator of WDF performs DOA estimation using different methods, such as Watson-Watt, correlative interferometry and highresolution (multiple signal classification - MUSIC and Root-MUSIC) in combination with different antenna arrays. The simulator is based on MATLAB ${ }^{\circledR}$ and can be easily used to teach the basic principles of DOA estimation, and to examine influence of various parameters on it, such as geometry and aperture of the antenna array, noise, spectrum occupancy, etc.
\end{abstract}

Key words: direction finder, wideband device, antenna array, signal generation, simulator, correlative interferometry, electronic surveillance.

\section{Introduction}

$\mathrm{I}_{\mathrm{s}}^{\mathrm{s}}$ this paper, an approach to design and development of the simulator of WDF for usage in the spectrum monitoring system has been described. Spectrum monitoring systems are very important in many applications, such as control of the electromagnetic spectrum by the national regulatory body [1] in civilian, or in military applications [2]. The purpose of WDF is to intercept and determine the DOA of all sources of the electromagnetic radiation, by the means of radio waves propagation properties. Considering this in general manner, WDF can be used to obtain the direction and location of a radio transmitter or a source of radio interference and noise. Because WDF is a highly complex technical system, its design and development is an interdisciplinary field and requires knowledge in different areas (antenna array, signal processing, high data rate processing, etc.). Selecting a WDF is delicate, because of the trade-off between operational request, performance and cost. In order to provide a tool for examination of WDF main characteristics, we have designed and developed the simulator of WDF in MATLAB ${ }^{\circledR}$, which is high-level language and interactive development environment, commonly used by researchers for system modelling and simulations.

Design and development of this simulator has been done in parallel with the development of $\mathrm{HF}$ and VHF/UHF direction finder in the Military Technical Institute (MTI). The aim of this work is to give researchers hands-on-experience via the development of WDF system. Using the developed simulator, researchers can be taught some initial theory and guidance on how to use or evaluate the results obtained from WDF in some specific situation in electromagnetic environment. Then, various stages of the basic WDF process can easily be seen and analyzed.

This paper includes some previous results and provides comprehensive knowledge to researchers about implementation of different techniques in modern WDFs. Using the proposed simulator, researchers have the possibility to investigate different methods and techniques that could be implemented in WDFs. The proposed simulator does not provide only estimation of DOA, it can also be used for verification of implemented methods and techniques of signal acquisition, signal processing and filtering. This simulator can also be used for teaching students about antenna array, digital signal processing and examination of different processors such as central processing units (CPUs) and graphics processing units (GPUs).

This paper consists of four sections. Introduction is given in Section I, architecture of the wideband direction finder in Section II, description of MATLAB-based simulator of wideband direction finder in Section III, and the final conclusions in Section IV.

\section{Architecture of WDF}

Modern WDF consists of DF's antenna array, acquisition and digital signal processing blocks. The basic architecture of modern WDF is presented in Fig.1 [3]. DF's antenna array is used to receive signals in the appropriate frequency band, and it consists of $L$ elements deployed to form uniform linear array (ULA), uniform circular array (UCA) or some specific DF's antenna array shapes, such as AD-COCK antenna array.

\footnotetext{
1) Military Technical Institute (MTI), Ratka Resanovića 1, 11132 Belgrade, SERBIA

Correspondence to: Ivan Pokrajac; e-mail: ivan.pokrajac@vs.rs
} 


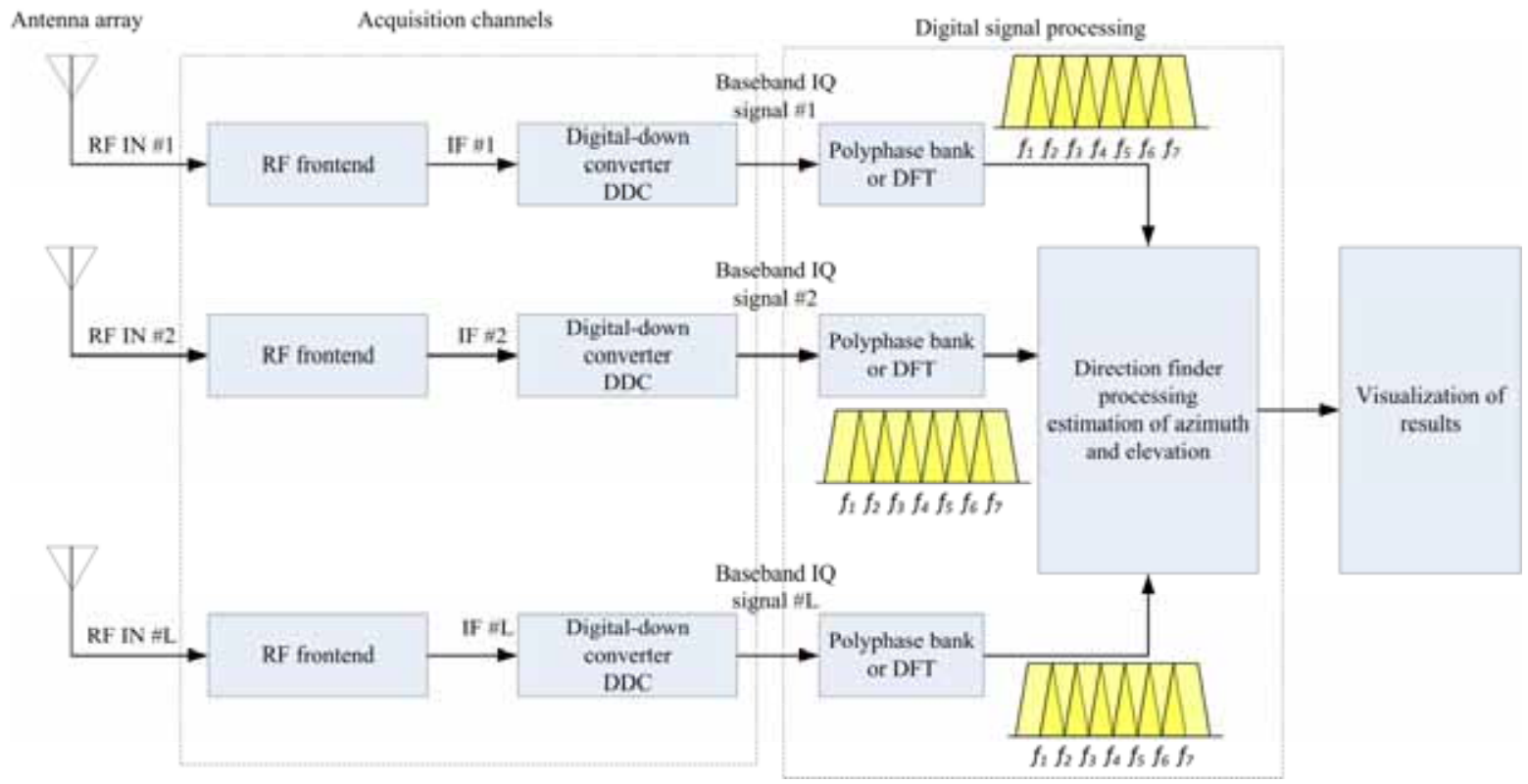

Figure 1. Basic architecture of WDF Acquisition block

Acquisition block includes RF frontend that converts RF signal to the appropriate intermediate frequency (IF), A/D convertors and Digital Down Convertors (DDCs) that convert IF signal to the baseband. The signal acquisition in DF may be performed using parallel or sequential techniques [1]. If it is parallel signal acquisition, the measurement of DOA is nearly instantaneous. Acquisition time in the case of sequential signal acquisition is longer than in the case of parallel acquisition, because measurement of DOA is done after the end of a sequence that involves antennas switching or weighting of signal from antennas. The sequential technique is used to reduce the number of receivers, and in that case, the number of receivers is smaller than the number of antenna elements.

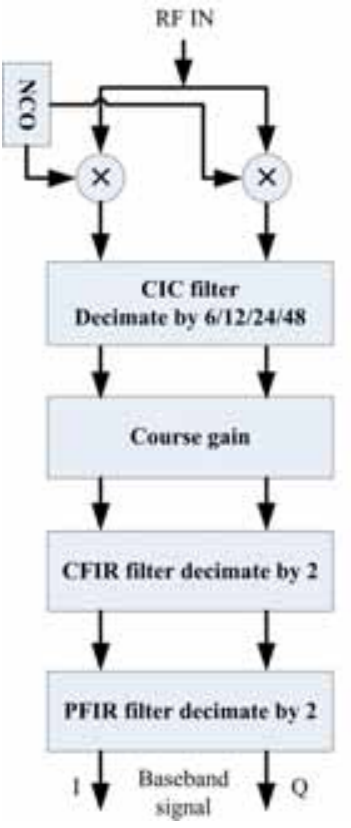

Modern WDF has to provide a very high probability of interception of signals. To fulfill this requirement, it is necessary to increase the instantaneous bandwidth or to decrease time for data processing (by increasing processing speed and processing power). In order to provide wider instantaneous bandwidth, at each acquisition channel it is possible to form more than one DDC and in that case each DDC covers a part of the instantaneous bandwidth. Using this approach, WDF can get wider instantaneous bandwidth that corresponds to the number of DDCs and theirs output sample rates. In the proposed simulator of WDF, each DDC consists of a Cascaded Integrator-Comb (CIC) filter, a Compensation FIR filter (CFIR), and a Programmable FIR filter (PFIR), as shown in Fig.2.

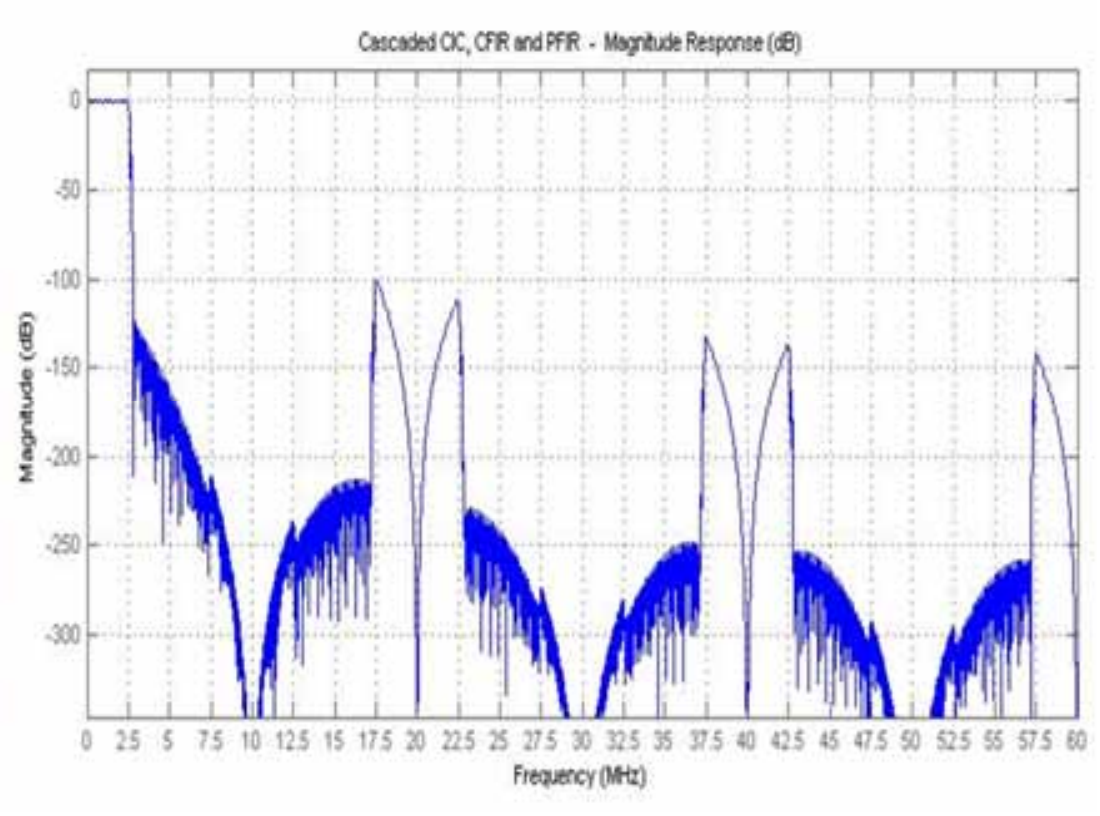

Figure 2. DDC and magnitude response of cascaded CIC, CFIR and PFIR filter

CIC filter is useful to realize large sample rate changes in digital systems. CFIR filter is used to flatten the passband frequency response. The low-pass PFIR filter is used to decrease the magnitude of the CIC filters ripples. The $20 \mathrm{MHz}$ instantaneous bandwidth of the WDF can be achieved by combining four DDCs at each acquisition channel. If input sample rate is set to $120 \mathrm{MHz}$, setting 6 as CIC decimation factor results in $5 \mathrm{MHz}$ PFIR output sample rate (CFIR and PFIR decimation factor is always 2). A magnitude response of cascaded CIC, CFIR and PFIR filter, for the previous scenario, is presented in Fig.2. In the proposed simulator it is possible to adjust input sample rate in DDC, or to adjust 
instantaneous bandwidth of WDF to some signal of interest (DVB-T, GSM, Wi-Fi ...), by changing total decimation factor of DDC. This can be useful in case when WDF is a part of a passive radar system.

For the practical implementation, we have used chipset TI GC4016 [4] at ICS 1554 4-Channel, 160/180 MHz 16-bit ADC PMC Module with Virtex-5 SX95T User Programmable FPGA (Fig.3).

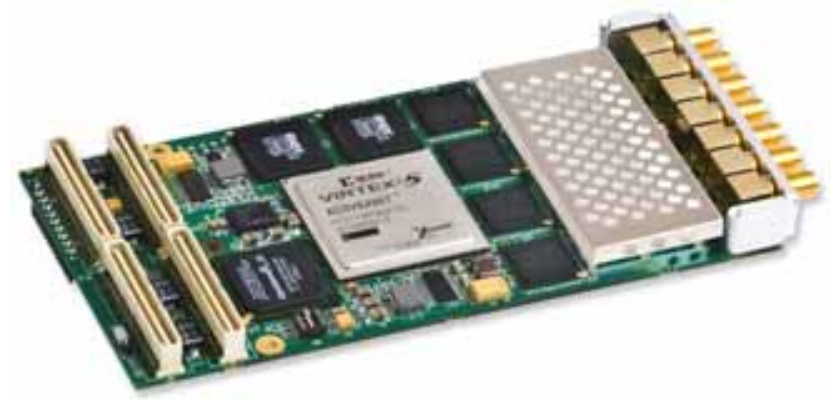

Figure 3. ICS 1554 4-Channel, 160/180 MHz 16-bit ADC PMC Module with Virtex-5 SX95T User Programmable FPGA [5]

\section{Digital signal processing block}

Block for digital signal processing consists of digital filter bank that converts signal from time domain into the frequency domain (i.e. its frequency spectrum) and part for estimation of DOA. After digital down-conversion to the baseband, the real and imaginary parts of the signal in each measurement path are fed to a digital filter bank, which is conventionally implemented as a Discrete Fourier Transform (DFT) or polyphase filter bank. During the next processing step, a quantity of samples determined based on the selected averaging time is collected and fed to the algorithms for DOA. This part of the processing typically involves the use of field programmable gate arrays (FPGAs).

DOA estimation in wideband direction finders has different concept then DOA estimation of wideband signals. DOA estimation of wideband signals can be performed in two different ways, which can be divided into two main groups: coherent and non-coherent [3] according to how information from the covariance matrices is used. In this simulator and in the development of WDFs a non-coherent approach has been used. The idea of trivial non-coherent DOA estimation of wideband signals is based on a non-coherent wideband processing. The non-coherent approach processes each frequency bin independently and average the DOA estimates over all the bins. Since each decomposed signal is approximated as a narrowband signal, any narrowband DOA estimation method is applicable. The position estimation at each frequency bin is separately processed and the final result is average over $J$ position estimation. In the real-world applications, the non-coherent focusing is most commonly used for the following reasons [3]:

- No a priori information is required;

- Almost all of the signals are already separated in spectral terms, and even with densely occupied scenarios, the signals can be separated in most cases with simple singlewave algorithms;

- Besides the DOA, frequency ranges occupied by the emitters can be estimated.

All radio DF use the differential signal delay across an antenna aperture to determine a signal DOA. Some systems such as phase interferometers measure the differential delay directly while others such as rotating loop systems or circularly disposed antenna arrays measure a function of the delay resulting in a directional antenna amplitude pattern. In the field of array signal processing, a class of DOA estimation methods has been developed based upon the eigenstructure of the array output covariance matrix. One well-known DOA estimation method is the multiple signal classification MUSIC. These DF techniques form sample covariance matrix from the collection of data snapshots from all antenna elements. This covariance matrix is used for further processing. Conventional MUSIC algorithm proposed in [6] uses subspace-based techniques for estimating the DOAs of multiple signal sources. This MUSIC algorithm involves a computationally demanding spectral search over the azimuth and elevation (2D search) and its implementation is expensive in real application. In order to decrease demand for 2D search in $[7,8]$ Root-MUSIC algorithm is proposed. Root-MUSIC algorithm estimates DOA via the zeros of a polynomial and the computationally expensive $2 \mathrm{D}$ search procedure required by conventional MUSIC is avoided. Root-MUSIC algorithm has been originally developed for the ULA because manifold vector of that array is a Vandermonde. In order to use RootMUSIC in a combination with the UCA some preprocessing technique for manifold transformation is required. The azimuthally dependence, structured as a Vandermonde, can be provided by preprocessing techniques.

In the proposed simulator two preprocessing techniques are implemented: manifold separation method [8] and beamspace transform [9] in combination with sequential signal acquisition and Root-MUSIC algorithm. Different implemented methods for DOA provide a possibility to researchers to compare these methods in order to examine their performances such as scanning speed of DF depending on the used method for DOA, accuracy, possibility to separate multiple signals at same frequency.

In this simulator of WDF and in the developed WDF we modified the known Real Beam-space MUSIC algorithm for uniform circular arrays (UCA-RB-MUSIC algorithm) for DOA estimation. Modification has been performed in order to use special UCA antenna array, such as AD-COCK antenna array. AD-COCK is UCA array with linear transformation of antenna array output. Signals from $L$ antenna elements are combined to form three channel antenna array output.

\section{MATLAB-based simulator of wideband direction finder}

An educational MATLAB based simulator has been primarily developed to give researchers hands-on-experience via the development of WDF system, but can also be used to teach the principles of DOA estimation to undergraduate and postgraduate students. This simulator is also used for some dedicated laboratory sessions, such as antenna array ambiguity analysis and digital signal processing techniques, including estimation of DOA. The developed program is graphical user interface (GUI) based. The first part of simulator is signal generator which can generate different scenarios on DF antenna array in the selected frequency band at chosen observed time period, and can perform 2D ambiguity analysis of the selected antenna array. GUI, with all basic blocks necessary to perform main WDF function of the implemented first part of simulator is shown in Fig.4.

\section{DF array output}

In the simulator for signal generation it is possible to select different antenna arrays such as ULA, UCA, special UCA (AD-COCK antenna array) or to import custom antenna arrays. In the temporal frequency domain the sensor outputs 
can be represented in a matrix-vector form as frequency dependent narrowband signals [10]:

$$
\mathbf{X}\left(f_{h}\right)=\mathbf{A}\left(\Theta, f_{h}\right) \cdot \mathbf{S}\left(f_{h}\right)+\mathbf{N}\left(f_{h}\right)(1)
$$

where the h-th frequency component is denoted by $f_{h}$, $h \in 1, H$, where $H$ is the total number of spectral components (frequency bins) for the selected frequency sub-band $f_{B W}$. Frequency-dependent steering matrix is $\mathbf{A}(\Theta, f)=\left[\mathbf{a}\left(\Theta_{1}, f\right)\right.$ $\left.\mathbf{a}\left(\Theta_{2}, f\right) \quad \ldots \quad \mathbf{a}\left(\Theta_{K}, f\right)\right]$ whose columns are steering vectors corresponding to $K$ signals. $K$ denotes the number of emitters that transmit signals which wave fronts impinge on the DF's antenna array from different directions $\Theta_{1}, \Theta_{2}, \ldots, \Theta_{K}\left(\Theta_{k}\right.$ represents azimuth $\theta_{k}$ and elevation $\varphi_{k}$ of the $k$ th signal). The assembly set of these steering vectors, for all the possible DOAs is defined as antenna array manifold. $\mathbf{X}(f)=\left[X_{1}(f) X_{2}(f) \ldots X_{L}(f)\right]^{T}$ where ()$^{T}$ denotes the transpose, is the finite time Fourier transform of the signals received from antenna array in the observed interval $T$; $\mathbf{S}(f)=\left[S_{1}(f) S_{2}(f) \ldots S_{K}(f)\right]^{T}$ is the finite time Fourier transform of $K$ signals down converted to baseband by frequency $f_{C}$ in the same observed interval; and $\mathbf{N}(f)=\left[N_{1}(f) N_{2}(f) \ldots N_{L}(f)\right]^{T}$ is the finite time Fourier transform of the interfering white Gaussian noise.

For signal generation, manual or automatic method can be used. In the manual method, an operator must enter all parameters for each one of the required signal, like modulation type, symbol rate, signal power, length (size of message), central frequency of each one in the observation bandwidth, azimuth and elevation. In the automatic method, an operator must specify only the number of signals, everything else is randomly calculated. Additionally, the simulator can simulate fixed-frequency or frequency hopping (FH) signals. Operator can choose fading in channel options, which can be one of Rayleigh, Rician, Weibull or Nakagami type (default channel is without fading, with additive white Gaussian noise - AWGN only). In the first part of the simulator, it is possible to generate signal at antenna array output using sequential and parallel techniques. In Fig. 4 the antenna array output for simulated scenario is shown (seven signals in the instantaneous bandwidth of $5 \mathrm{MHz}$ at $f_{c}=2.4$ $\mathrm{GHz}$ ).

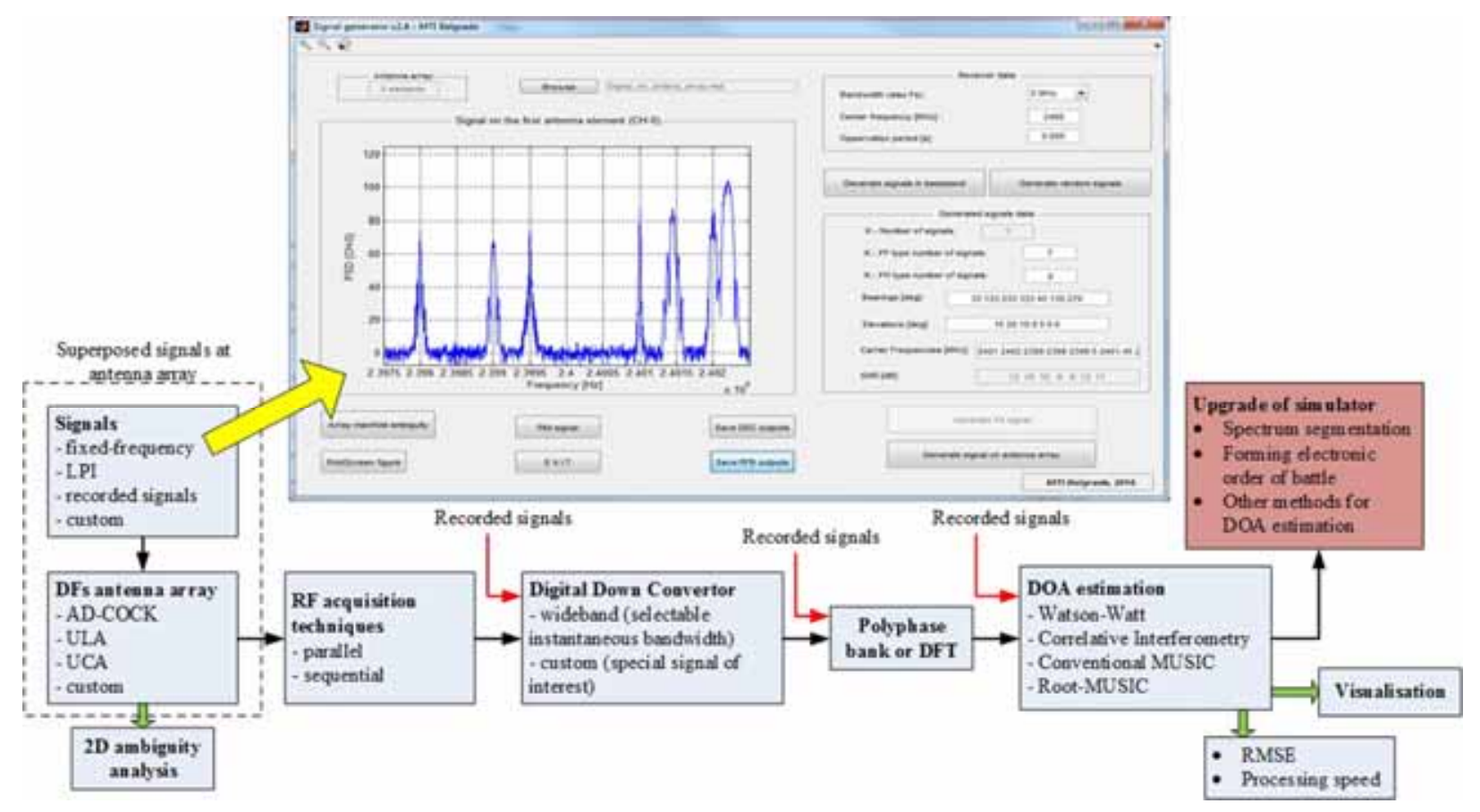

Figure 4. Concept of the proposed simulator of WDF

\section{$2 D$ ambiguity analysis of direction finding}

Simulator for signal generation can be used to perform 2D ambiguity analysis of DF, which comes from two sources: antenna array and DOA estimation algorithm ambiguities. To get the uniform DOA resolution irrespective of DOAs, the effective aperture of antenna array should be independent from the DOA. UCA fulfills this requirement, and it is adequate solution for WDF applications. By increasing the antenna array radius, the resolution of spatial spectrum is improved. However, increasing the antenna array radius without increasing number of antenna elements leads to the spurious peaks in the spatial spectrum. These spurious peaks make impossible to discriminate real DOA from spurious. In order to present this effect, in the proposed simulator a function that treats a type I ambiguity problem is implemented, which measures the correlation of the array steering vectors $\mathbf{a}(\Theta, f)$ and occurs when
$\mathbf{a}\left(\Theta_{i}, f_{h}\right)=\mathbf{a}\left(\Theta_{j}, f_{h}\right)$, for $\Theta_{\mathrm{i}} \neq \Theta_{\mathrm{j}}$ [11]. Type I Ambiguity function can be defined as such:

$$
\chi\left(\Theta_{i}, \Theta_{j}\right)=\left|\frac{\boldsymbol{\alpha}\left(\Theta_{i}\right)^{*} \cdot \boldsymbol{\alpha}\left(\Theta_{j}\right)}{\left\|\boldsymbol{\alpha}\left(\Theta_{i}\right)\right\| \cdot\left\|\boldsymbol{\alpha}\left(\Theta_{j}\right)\right\|}\right|
$$

where $\|\quad\|$ is a norm of vector [11].

An example of using this ambiguity for WDF ULA and UCA antenna array is presented in Fig.5. It is assumed that antenna array consists of 5-elements with characteristic frequency $f_{A}$ that corresponds to the wavelength which is equal to diameter of array in the case of UCA, or total length of ULA. Signals are at frequency $f_{C}=2.4 \mathrm{GHz}$ and elevation is assumed to be $\varphi_{1}=\varphi_{2}=5^{\circ}$. Based on the obtained results, it can be concluded that UCA exhibits better performances than ULA, because of dominant spurious peaks in the case of ULA. 


\section{Methods for DOA estimation}

Standard methods for DOA estimation in WDF are correlative interferometer and Watson-Watt, but some modern WDFs also implement high-resolution methods, such as MUSIC.

\section{a) Correlative interferometer methods for DOA estimation}

Phase interferometry method for DOA estimation is based on measuring the phase differences among the responses of the antenna array elements to the arriving signal. Phase interferometry can be divided into two groups: based on measuring phase differences between the responses of the

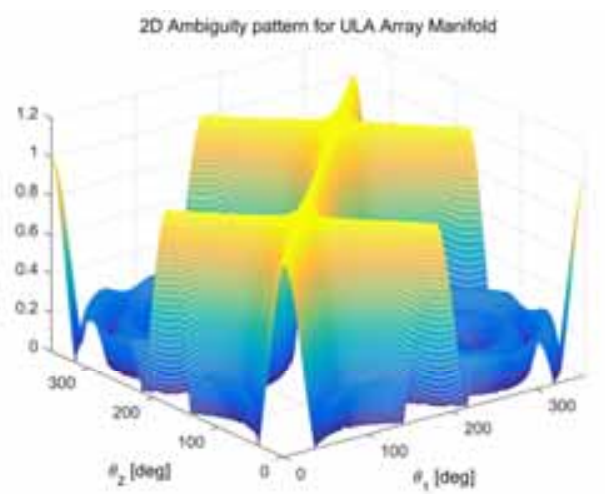

a)

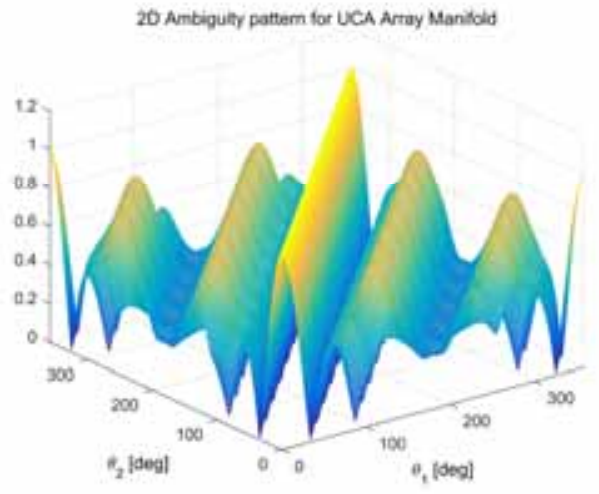

b)

Figure 5. 3D and contour plot $\chi\left(\Theta_{i}, \Theta_{j}\right) \geq 0.8$, of the array manifold ambiguity: a) 5-element ULA; b) 5-element UCA

The correlative interferometry DF method can be divided into two steps. The first step is used for forming the correlation coefficient of the two data sets. The second part is used for precise estimation by parabolic approximation [12]. The first step is to estimate the correlation coefficients creating correlation matrix:

$$
\mathbf{R}_{X Y}=\frac{\mathbf{X}_{M} \cdot \mathbf{X}_{R}^{*}}{\left[E\left\{\left|\mathbf{X}_{M}\right|^{2}\right\} \cdot E\left\{\left|\mathbf{X}_{R}^{*}\right|^{2}\right\}\right]^{1 / 2}}
$$

where $\mathbf{X}_{M}$ is measured phase difference vector and $\mathbf{X}_{R}$ is stored phase difference from the lookup table.

Although knowing correlation coefficients of $\mathbf{R}$ continuums makes it easy to determine global maximum, there is still a problem of significant usage of memory space and processing time. Instead of that, it is more efficient to set correlation coefficients in discreet samples and then to locate maximums of correlation coefficients of these discreet data by using interpolation or curve fitting. Algorithm that is used for curve fitting of correlation coefficients implies that the curve can be approximated by parabola near its maximum value. In the case of correlation coefficients parabolic approximation of antenna array elements and correlation based method (correlative interferometer) [12]. The basic principle of the correlative interferometer method is based on comparing the measured phase differences between the responses of the antenna array elements with the phase differences obtained from the DF antenna system of known configuration at a known DOA, the reference spatial signal (RSS). The comparison is performed by calculating the quadratic error or the correlation coefficients of the two data sets. If the comparisons are made for different azimuth values of the reference data set, the DOA is obtained from data for which the correlation coefficients are at a maximum.
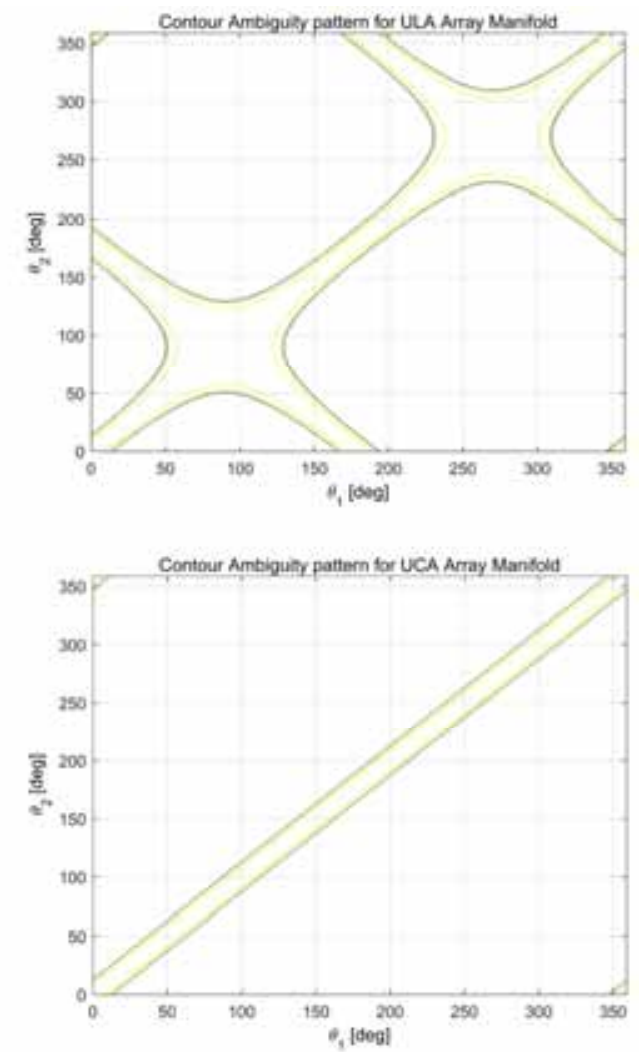

elevation, additional transformation of its coordinates is needed, because the curve is not symmetric near its maximum value.

In the case of averaging, the signal blocks are formed on each antenna for the selected output from Polyphase filter bank (PFB). Averaged value is the arithmetic mean of all values in blocks. The first averaging method refers to averaging the signal samples (outputs from the PFB) $\hat{\mathbf{x}}_{M}=\frac{1}{N} \sum_{i=1}^{N} \mathbf{x}_{M i}$ where $X_{M}$ is a vector of signal samples after the PFB. In the second case, phase differences vectors are averaged $\hat{\mathbf{X}}_{M}=\frac{1}{N} \sum_{i=1}^{N} \mathbf{X}_{M i}$, and in the the third case, the correlation coefficients matrix $R$ has been averaged $\hat{\mathbf{R}}_{X Y}=\frac{1}{N} \sum_{i=1}^{N} \mathbf{R}_{X Y i}$.

\section{b) High-resolution (MUSIC) methods for DOA estimation}

There are numerous effective techniques for DOA estimation that can be implemented in DF such as maximum 
likelihood estimation (ML), the minimum variance distortionless-response algorithm (MVDR), multiple signal classification (MUSIC) and estimation of signal parameters via rotational invariance techniques (ESPRIT) [3]. These DF techniques form sample covariance matrix from the collection of data snapshots from all antenna elements. This covariance matrix is used for further processing. The spectral covariance matrix of the received signal is expressed by:

$$
\begin{aligned}
& \mathbf{R}_{X X}\left(f_{h}\right)=\mathbf{X}\left(f_{h}\right) \mathbf{X}^{H}\left(f_{h}\right)= \\
& =\mathbf{A}(\Theta) \cdot \mathbf{R}_{S S}\left(f_{h}\right) \cdot \mathbf{A}(\Theta)^{H}+\sigma^{2} \mathbf{I}
\end{aligned}
$$

where $(\cdot)^{H}$ denotes conjugate transpose, and where $\mathbf{R}_{S S}\left(f_{h}\right)$ is the spectral covariance matrix of the transmitted signals at $h$ th spectral component, I represents the identity matrix dimension $L \times L$ and $\sigma^{2}$ is noise covariance. In the proposed algorithm the spectral covariance matrix $\mathbf{R}_{X X}\left(f_{h}\right)$ is evaluated at selected frequency on each frequency bin in the observed frequency sub-band for DOA estimation. The MUSIC algorithm involves a computationally demanding spectral search over the azimuth and elevation (2D search) and its implementation is expensive in real application.

In order to decrease complexity of DOA estimator using Root-MUSIC, it is required to work with arrays having a steering vector with the Vandermonde structure. There are numerous developed preprocessing techniques which can be used to map the steering vector of UCA onto the manifold vector of ULA with proper Vandermonde structure. In the proposed simulator of WDF manifold separation preprocessing techniques and Beamspace transform have been implemented. The manifold separation method [8] is based on forming element-space steering vector of a UCA as a product of matrix characteristics for the array itself and a Vandermonde structured vector that depends on the azimuth angle. The manifold separation method does not require dividing the whole $360^{\circ}$ coverage into angular sectors. The manifold separation may be rewritten as a last-square (LS) problem as:

$$
\arg \min _{\mathbf{G}}\left\{\sum_{t=1}^{T}\left\|\mathbf{a}\left(\theta_{t}\right)-\mathbf{G d}\left(\theta_{t}\right)\right\|_{F}^{2}\right\}
$$

where $\mathrm{T}$ is the number of azimuths uniformly distributed over $[02 \pi), \mathbf{G}$ is the $L \times M_{l}$ characteristic matrix, $M_{l}$ is the number of selected modes and $\mathbf{d}\left(\theta_{t}\right)$ is the Vandermonde vector dimension $M_{l} \times 1$ defined for azimuth $\theta_{t}$ as:

$$
\mathbf{d}\left(\theta_{t}\right)=\left[\begin{array}{lllllll}
e^{-j \frac{M_{1}-1}{2} \theta_{t}}, & \ldots, & e^{-j \theta_{t}} & 1 & e^{j \theta_{t}} & \ldots & e^{j \frac{M_{1}-1}{2} \theta_{t}}
\end{array}\right]^{T}
$$

The optimization problem in (6) can be solved by choosing $T>>L$. Matrix $\mathbf{G}$ can be found minimizing the sum of squared errors as:

$$
\mathbf{G}=\mathbf{A} \mathbf{D}^{H}\left(\mathbf{D} \mathbf{D}^{H}\right)^{-1}
$$

where $\mathrm{D}$ is the matrix dimension $M_{1} \times T$ whose columns are Vandermonde vectors defined for different azimuths $\mathbf{D}=\left[\mathbf{d}\left(\theta_{l}\right), \ldots, \mathbf{d}\left(\theta_{T}\right)\right]$.

By exploiting the concept of manifold separation equation (4) can be rewritten as:

$$
\mathbf{X}\left(f_{h}\right)=\mathbf{G D} \cdot \mathbf{S}\left(f_{h}\right)+\mathbf{N}\left(f_{h}\right)
$$

The UCA-MS-MUSIC spectrum can be expressed as:

$$
P_{R M}(\theta)=\frac{1}{\mathbf{d}^{H}(\theta) \mathbf{G}^{H} \mathbf{U}_{n} \mathbf{U}_{n}^{H} \mathbf{G d}(\theta)}
$$

where $\mathbf{U}_{\mathrm{n}}$ is noise subspace matrix, dimension $L \times(L-K)$.

Beamspace transform [9] maps the steering vector of a $\mathrm{UCA}, \mathbf{a}(\theta)$ into $M_{1} \times 1$ Vandermonde structured steering vector of ULA $\mathbf{a}_{\mathrm{e}}(\theta)$. The transformation from element space to beamspace is performed multiplying vector $\mathbf{a}(\theta)$ with corresponding beamformer matrix $\mathbf{F}_{\mathrm{e}}, \mathbf{a}_{e}(\theta) \approx \mathbf{F}_{e}^{H} \mathbf{a}(\theta)$. The beamformer matrix $\mathbf{F}_{\mathrm{e}}$ is based solely on the principle of phase mode excitation. $M$ denotes the highest order mode that can be excited by the aperture at a reasonable strength and it is determined as $M \approx k_{0} r=2 \pi \cdot r / \lambda$, where $\mathrm{r}$ is radius of UCA and $\lambda$ is wavelength. Without entering into a detailed analysis, the UCA-RB-MUSIC spectrum can be expressed as:

$$
P_{R M}(\theta, \varphi)=\frac{1}{\mathbf{v}^{H}(\theta) \mathbf{J}(\xi) \mathbf{W} \mathbf{U}_{n} \mathbf{U}_{n}^{T} \mathbf{W}^{H} \mathbf{J}(\xi) \mathbf{v}^{H}(\theta)}
$$

where vector $\mathbf{v}(\theta)$ is similar in form to the ULA manifold vector, the elevation dependence takes the form of a symmetric amplitude taper through the matrix of Bessel function $\mathbf{J}(\xi)=\operatorname{diag}\left\{J_{M}(\xi), \ldots, J_{1}(\xi), J_{0}(\xi), J_{1}(\xi), \ldots, J_{M}(\xi)\right\}$ where $J_{M}(\xi)$ is Bessel function of the first kind of order $M$, $\xi=k_{0} r \cos (\phi)$ and matrix $\mathbf{W}$ is defined as: $\mathbf{W}=\frac{1}{\sqrt{M_{1}}} \cdot\left[\mathbf{v}\left(\alpha_{-M}\right)|\ldots| \mathbf{v}\left(\alpha_{0}\right)|\ldots| \mathbf{v}\left(\alpha_{M}\right)\right], \quad$ where

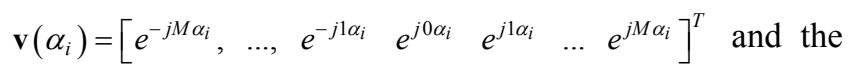
angles $\alpha_{i}=2 \pi \frac{i}{M_{1}}, i \in[-M, M]$.

The following tables show part of the MATLAB code for implementation of the proposed beamspace transformation for Root-MUSIC method in combination with AD-COCK antenna array. In the open literature, there is no similar solution. The proposed method uses knowledge how to present array manifold of the AD-COCK antenna array (ADCOCK antenna array is an UCA with $L=4 n$ elements, $n=1,2, \ldots N)$. Using linear combination from $L$ elements, three antenna outputs of AD-COCK antenna array are formed.

\section{DOA estimation}

In this part, we present results of DOA estimation using implemented correlative interferometer and Root-MUSIC methods.

In Fig.6a DOA estimation is shown, using correlative interferometer method in case when seven signals are superposed at UCA in the instantaneous bandwidth of $5 \mathrm{MHz}$ at central frequency of $2.4 \mathrm{GHz}$. In Fig.6b DOA estimation is shown, using Root-MUSIC method (in combination with manifold separation pre-processing techniques) in case when six signals are superposed at UCA in the instantaneous bandwidth of $5 \mathrm{MHz}$ at central frequency of $390 \mathrm{MHz}$. There are more superpose signals at the same carrier frequency.

By using the proposed simulator it is possible to examine performances of the methods for DOA estimation in combination with different techniques of signal acquisition and pre-processing. 
Table 1. MATLAB code for implementation of the beamspace transformation Root-MUSIC method in combination with AD-COCK antenna array

\begin{tabular}{|c|}
\hline 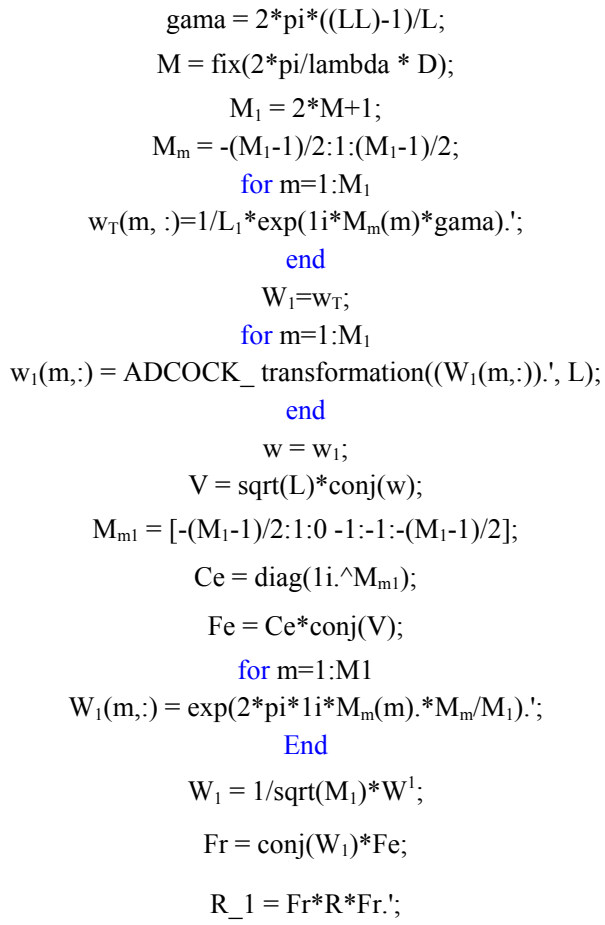 \\
\hline
\end{tabular}

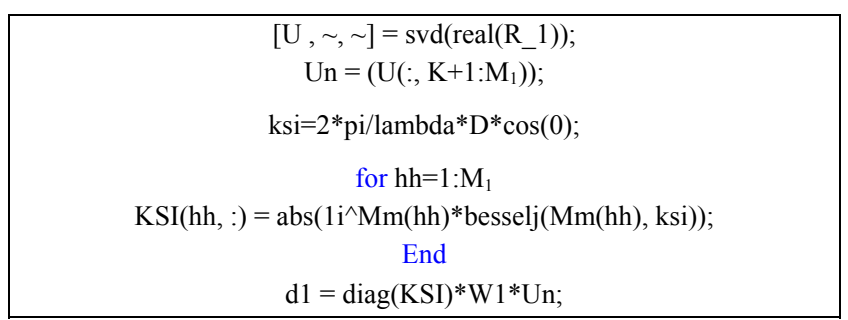

Table 2. MATLAB code for Transformation of the UCA beamforming weight vector $\mathbf{W}_{1}$ to the AD-COCK beamforming weight vector $\mathbf{w}$

\begin{tabular}{|c|}
\hline 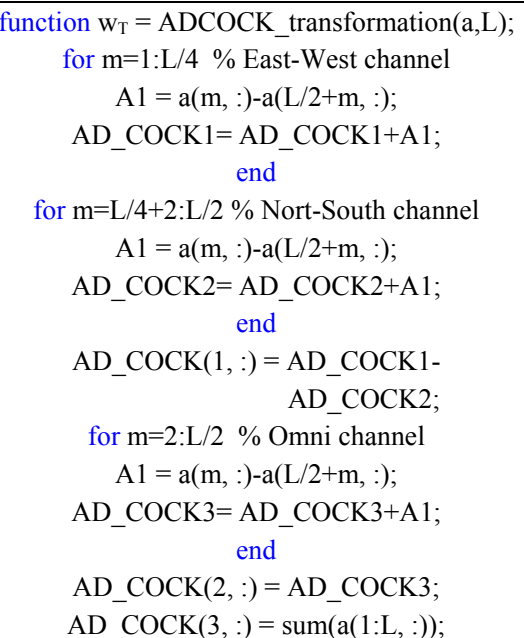 \\
\hline
\end{tabular}

a)

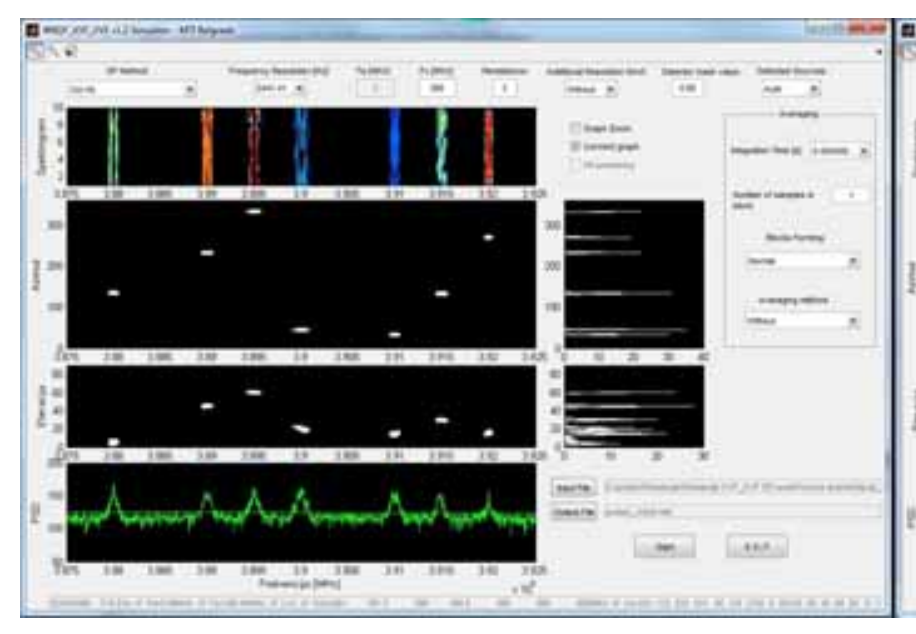

Figure 6. DOA estimation in WDF: a) using correlative interferometer; b) using Root-MUSIC

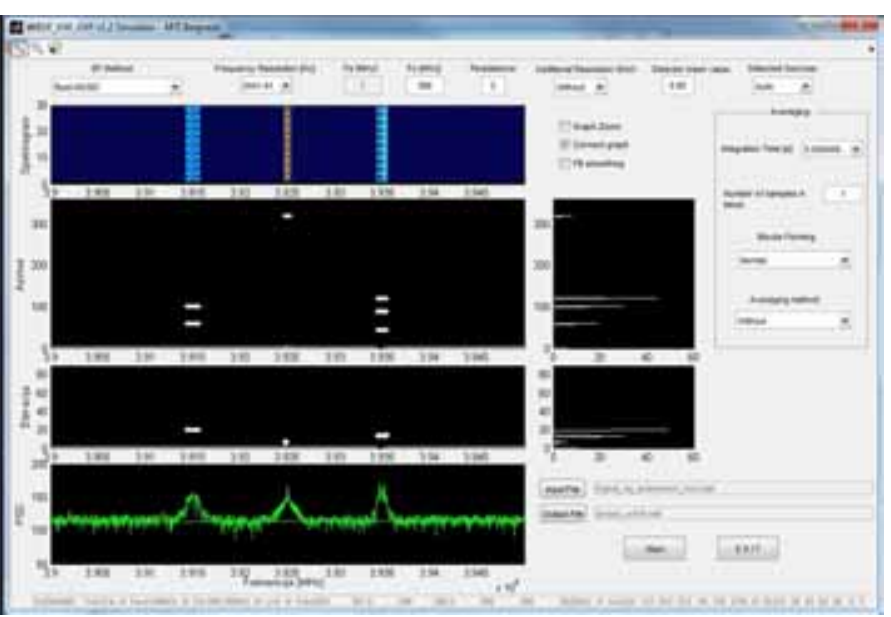

b)

\section{Conclusions}

To provide effective tool that can be useful for researchers, with the possibility to be continuously upgraded with new functions, in this paper the simulator of WDF, implemented in MATLAB, has been proposed. Initially, the users of the proposed simulator could generate different scenarios of the signal on the DF's antenna array. In the second step, the proposed simulator provides users the possibility to investigate different combination of techniques and methods in every block of signal processing that is usually used in modern WDF. This simulator provides a lot of possibility during the process of WDF development. Also, it has the possibility to form a large scenario database with simulated signals on DF's at antenna array, which can be useful in case when the simulator is used as an educational tool in the process of WDF operators training, or to teach students the basic principles of WDF systems.

\section{References}

[1] International Telecommunication Union, Handbook Spectrum Monitoring, Radio communication Bureau, Geneva, Switzerland, 2011.

[2] POKRAJAC,I., OKILJEVIC,P., VUČIĆ,D.: Fusion of multiple estimation of emitter position, Scientific Technical Review, ISSN 1820-0206, 2012, Vol.62, No.3-4, pp.55-61.

[3] TUNCER,T.E., FRIEDLANDER,B.: Classical and modern directionof-arrival estimation, Academic Press, USA, 2009.

[4] Texas Instruments, TI GC4016, www.ti.com/product/gc4016 [Accessed on March 12, 2015].

[5] GE Fanuc Intelligent Platforms Announces ICS-1554 Digital Receiver, www.geautomation.com, accessed on November 08, 2016. Accessible at URL: http://www.geautomation.com/news/ge-fanuc-intelligentplatforms-announces-ics-1554-digital-receiver/n1094

[6] SCHMIDT,R.O.: Multiple emitter location and signal parameter estimation, IEEE Transactions on Antennas and Propagation, 1986, Vol.34, No.3, pp.276-280.

[7] ROALD,G., ROGIER,H., WERBROUCK,S.: UCA Root-MUSIC with sparse uniform circular arrays, Signal Processing, IEEE Transactions, 2008, Vol.56, No.8, pp.4095-4099. 
[8] BELLONI,F., RICHTER,A., KOIVUNEN,V.: Extension of rootMUSIC to non-ULA Array Configuration, Proceedings of the IEEE International Conference on Acoustics, Speech, and Signal Processing (ICASSP), Toulouse, France, 14-19. May 2006.

[9] ROALD,G., ROGIER,H.: A hybrid UCA-RARE/Root-MUSIC approach for 2-D direction of arrival estimation in uniform circular arrays in the presence of mutual coupling, Antennas and Propagation, IEEE Transactions, 2007, Vol.55, No.3, pp.841-849.

[10] POKRAJAC,I., VUCIC,D.: Wideband cyclic music algorithms: A frequency-domain approach, Facta universitatis-series: Electronics and Energetics, 2010, Vol.23, No.3, pp.367-378.
[11] KUANG,W.,XIN,Z., XIANJUN,J., CANFENG,C.: 3-D ambiguity analysis method of arbitrary antenna array for direction finding, Wireless Symposium (IWS), IEEE International, 24-26 March 2014, Electronic, ISBN 978-1-4799-3403-4

[12] Cheol-Sun Park, Dae-Young Kim: The Fast Correlative Interferometer Direction Finder using I/Q Demodulator, Asia-Pacific Conference on Communications, 2006, APCC '06. DOI: 10.1109/APCC.2006.255915, pp.1-5.

\title{
Projektovanje i razvoj simulatora širokopojasnog radio-goniometra
}

Sa ciljem da se obezbedi alat za dizajn i razvoj širokopojasnih radio-goniometara, predložen je simulator širokopojasnog radio-goniometra. Svrha rada je da se istraživačima, studentima i korisnicima širokopojasnih radio-goniometara pruži iskustvo u radu širokopojasnog radio-goniometra. Simulator se sastoji od dva glavna dela: prvi deo za generisanje superponiranog signala na antenskom nizu radio-goniometra i drugi deo za simulaciju akvizicije signala i obradu signala (implementacija metoda za procenu smera dolaska signala). Korišćenjem predloženog simulatora, istraživači ili studenti imaju mogućnost da generišu različite scenarije u radio-frekvencijskom spektru sa različitim tipovima emisija. Simulator širokopojasnog radio-goniometra vrši procenu smera dolaska signala korišćenjem različitih metoda, kao što su Watson-Watt, korelativna interferometrija, i visoko-rezolucione metode (MUSIC i Root-MUSIC), u kombinaciji sa različitim tipovima antenskih nizova. Simulator je izrađen u MATLAB ${ }^{\circledR}$ i može se lako koristiti za učenje osnova procene smera dolaska signala i ispitivanje uticaja različitih parametara na procenu, kao što su geometrija i otvor antenskog niza, šum, zauzetost spektra, itd.

Ključne reči: radio-goniometar, širokopojasni uređaj, antenski niz, generisanje signala, simulator, korelativna interferometrija, elektronsko izviđanje.

\section{Проектирование и разработка симулятора широкополосного радиопеленгатора}

\begin{abstract}
С целью обеспечения инструментов для проектирования и разработки широкополосных радиопеленгаторов (WDF) в этой статье предложен симулятор широкополосного радиопеленгатора. Цель исследования состояла в том, чтобы исследователям, студентам и пользователям широкополосного радиопеленгатора был обеспечен опыт в работе с широкополосным радиопеленгатором. Симулятор состоит из двух основных частей: первая часть используется для генерирования наложенного сигнала на выходе антенной решётки радиопеленгатора и вторая часть используется для захвата сигнала моделирования и обработки сигналов (реализация методов для оценки направления прихода сигнала). При использовании предлагаемого симулятора, исследователи или студенты имеют возможность создавать различные сценарии в радиочастотном (RF) спектре с различными видами излучений. Симулятор широкополосного радиопеленгатора оценивает направление прихода сигналов с использованием различных методов, таких как Watson-Watt, корреляционная интерферометрия и методы высокой резолюции (MUSIC и Root-MUSIC), в сочетании с различными типами антенных решёток. Симулятор изготовлен на основе MATLAB® и может быть легко использован для изучения основ оценки направления прихода сигнала и для проверки влияния различных параметров на оценки, таких как геометрия и апертуры антенной решётки, шума, занятости спектра и т.д.
\end{abstract}

Ключевые слова: радиопеленгатор, широкополосное устройство, антенная решётка, генерирование сигнала, симулятор, корреляционная интерферометрия, электронное наблюдение

\section{Conception et développement du simulateur large bande de radiogoniométrie}

Dans le but de fournir les outils pour la conception et le développement des radiogoniomètres de large bande(WDF) on a proposé un simulateur de radiogoniomètre WDF. Le but de ce travail est d'offrir l'expérience de travail de radiogoniomètre WDF aux chercheurs, étudiants et utilisateurs. Le simulateur se compose de deux parties principales : la première sert à générer le signal superposé sur le réseau d'antennes du radiogoniomètre tandis que la seconde est destinée à simuler l'acquisition et le traitement des signaux (implémentation des méthodes pour évaluer la direction d'arrivée des signaux). Par l'emploi du simulateur proposé les chercheurs et les étudiants ont la possibilité de créer les scénarios variés dans le spectre de radio fréquences avec les différents types d'émissions. Ce simulateur effectue l'évaluation de la direction de l'arrivée des 
signaux au moyen de différentes méthodes telles que Watson Watt, interférométrie corrélative, les méthodes de haute résolution (MUSIC et Root- MUSIC) en combinaison avec les différents types des réseaux d'antennes. Le simulateur a été produit à MATLAB et peut s'utiliser facilement pour apprendre les bases de l'estimation de la direction d'arrivée des signaux ainsi que pour les essais sur l'influence de divers paramètres d'estimation tels que la géométrie et l'ouverture du réseau d'antennes, bruit, occupation du spectre, etc.

Mots clés: radiogoniométrie, instrument large bande, réseau d'antennes, création des signaux, simulateur, interférométrie corrélative, reconnaissance électronique. 